\title{
Stress related components in patients with acute myocardial infarction
}

\author{
Carlo Pruneti*, Federica Giaroli and Sara Guidotti \\ Department of Medicine and Surgery, Clinical Psychology, Clinical Psychophysiology and Clinical Neuropsychology Labs, University of Parma, Italy
}

\begin{abstract}
Objective: The present work aims to describe the psychological characteristics emerging in a group of infarcted subjects using tests to detect some aspects of the personality and typical behaviours of patients who have been diagnosed with serious cardiovascular disease. In the scientific literature, a number of biological predispositions have been already identified and well described such genetic predisposition, sex, age, hypercholesterolemia, hypertension etc.

Furthermore, multiple psychological factors: personality traits, the ability or to feel emotions, like an-ger and hostility, particular behavioural patterns and lifestyles, seems to plays an important role in the etiology of cardiovascular diseases.

In addition, as evidence of the close body-mind relationship and the importance of the patient's over-all management, there is the fact that pathological alterations of the mood can be risk factors about the course of most of organic disease and even represent real predictors of mortality.

Materials and methods: 25 subjects ( 23 male and 2 female) aged between 40 and 60 with a diagnosis of Acute Myocardial Infarction were examined. The following tests were administered before angioplasty: Symptom Questionnaire, Illness Behaviour Questionnaire and P Stress Questionnaire. After two weeks, during the cardiological rehabilitation, the Cognitive Behavioural Assessment battery and a second Symptom Questionnaire were administered.

Results: The results in the P Stress Questionnaire highlight dysfunctional behaviours; in particular, patients show high scores in the Hyperactivity and Vigor subscales while the Illness Behaviour Questionnaire highlights the tendency to deny emotions. In addition, comparing the results between the first and second administration of the Symptom Questionnaire reveals a decrease in hostility.

Conclusions: This study confirms what has already been described in the literature about the presence of stable personality traits and the tendency to adopt risky behaviours for stress-related physical disorders in a group of infarcted patients and highlights the need for a multidimensional and multidisciplinary approach in order to promote psychological well-being, encourage the improvement of physical conditions and prevent any relapses.
\end{abstract}

\section{Introduction}

In the scientific literature, it is frequent to note an ever-wider importance, given by both clinicians and researchers, to psychological, environmental, and social aspects involved in the genesis and in the maintenance of even serious diseases, including cardiac ones [1-4]. However, this important finding is not always followed by an agreed psychological and psychophysiological assessment scheme to be associated with the clinical-medical diagnosis for an increasingly correct and optimal way of care, treatment and rehabilitation, in particular for the infarcted patient [1].

The work of the cardiologist is indispensable and irreplaceable but such serious and disturbing organic pathologies for the relational life of individuals are always associated with a series of psycho-logical and emotional components that cannot be overlooked. It is therefore important to describe, illustrate and understand them in order to get to an optimal and long-lasting treatment procedure, if not even to a complete healing $[2,5]$.

Although it has been recognized that stress, some personality factors and some potential psycho-pathological tendencies have an influence on the etiology of cardiovascular disorders, the precautionary measures implemented to deal with the problem are still too limited. In addition, there are not until now, many cardiac units in which patients can benefit from a targeted psychological and psychophysiological assessment and counselling [1].
It is also to be considered that, beyond the peculiar characteristics of the heart patient; any disease condition that imposes hospitalization is potentially cause of distress [6,7]. In fact, an important hospitalization can turn into a real "spoliation" of the patient who risks losing his individual and social characteristics, of being reduced to a simple number, labelled only as a "clinical case" [6]. In this case, anguish, fears and anxieties need to be communicated to those who are able, by professionalism, to welcome, understand and motivate them, helping the individual, according to his peculiar characteristics, to manage them to the best of his ability $[8,9]$.

Reconfirming the presence of a wire that has always connected the mind to the body, reaffirming the well-known influence of psychological well-being on the physical one may seem simple and obvious, but the problem is now of a different nature. It is necessary to provide for the implementation of multidisciplinary interventions, which include

${ }^{\star}$ Correspondence to: Carlo Pruneti, Department of Medicine and Surgery, Clinical Psychology, Clinical Psychophysiology and Clinical Neuropsychology Labs, University of Parma, Italy, Tel: 3926000843; E-mail: carlo.pruneti@unipr.it

Key words: acute myocardial infarction, type a behaviour, physical stress-related disorders, mind-body inte-gration, cardiovascular rehabilitation

Received: December 11, 2020; Accepted: December 23, 2020; Published: December 28, 2020 
both dimensions in a homogeneous body capable of guaranteeing, in respect of the various competences, the best possible result of the treatments. Cardiovascular research highlights the importance of a person-centered care through individualized psychosocial support and creating a sense of empowerment for the individual concerned, to support positive lifestyle changes after a cardiac event $[1,2,5]$. There is a need for an approach aimed at a global take care of the human being, beyond the usual taking care of the disease.

\section{Aim of the research}

The present work aims to describe the psychological characteristics emerging in a group of infarcted subjects.

Using standardized psychological tests, some personality aspects and behavioral peculiarities typical of patients who have been diagnosed with serious cardiovascular disease have been assessed.

A number of biological predispositions have been identified and described in literature (family and genetic factors, sex, age, hypercholesterolemia, hypertension etc.) as well as psychological factors including personality traits, the ability or not to feel emotions - including anger and hostility - particular behavioral patterns and lifestyles that all seem to play an important role $[9,10]$. It has been found that people suffering from serious cardiovascular disorders, and in particular from myocardial ischemia, show a particular and typical behavioral configuration (defined Type A behavior) characterized by such identifiable patterns: exaggerated ambition, competitiveness, personal quest for success and very high levels of performance, aggression and hostility [11-13]. Numerous studies have shown that subjects with high levels of hostility have a much higher incidence of heart disease [10-12,14-17]. In particular, repressed anger would seem to be a high-risk index as well as the inability to manage adequately the emotional states; this implies particularly intense physiological reactions to stress that can lead, for example, to myocardial ischemia [14-17].

The way in which a stress condition can cause coronary artery spasm implies the activation of various neuro-hormonal regulation mechanisms. In this process the stress response, that can be predisposing or triggering cause of the myocardial infarction, is fully inserted, contributing to develop or accelerate coronary arteriosclerosis through the involvement of the hypothalamus-pituitary-adrenocortical (HPA) axis, which leads to secretion of catecholamine and cortisol $[18,19]$.

In addition, as evidence of the close body-mind relationship and the importance of the patient's overall management, there is the fact that alterations of the mood can be characterized as risk factors about the course of the organic disease and even represent real predictors of mortality.

In fact, even if the patient survives hospital stay, there is a 10 to $30 \%$ probability that he will die within 2 years and this figure correlates with age but also with the presence of depressive symptoms (Vaccarino et al., 2001) [20]. In particular, several studies have shown how the presence of a depressive symptomatology can increase the risk of mortality in patients with coronary heart disease and how this strongly correlates with the severity of the disorder. It is well known that two years after the post-intervention, the risk of death of patients with mild depressive symptoms is two times higher than that of non-depressed patients and is three times higher in those patients with major depressive disorder [21]. In a more recent study it emerged, that depression constitutes a risk factor even after 5, 10 and 15 years from the myocardial infarction regardless of the severity of the same and the age of the patient [22].
This can be explained by the imbalance of the psychophysiological structure and therefore by the autonomic and endocrine hyperarousal, again, through the activation of the HPA axis (Musselman, Evans \& Nemeroff, 1998) [23]. There is also the involvement of immunological mechanisms (e.g. pro-inflammatory cytokines such as interleukins or tumor necrosis factor) which are associated with an increased risk of coronary heart disease [24-26]. Finally, psychosocial and behavioral factors, such as the adoption of risky behavior and/or low adherence to medical prescriptions, can be involved [21].

In the present study, the authors expect to detect individual characteristics that predispose to the onset of stress-related physical disorders, such as cardiovascular diseases, in the sample. In particular, the author assumes that a general tendency to denial of illness and emotions (evident in the Illness Behavior Questionnaire), among which also anger and hostility, can be described; in addition, the authors expect to find a tendency to adopt maladaptive lifestyles characterized by hyperactivity and vigor (observable in the P Stress Questionnaire). It is possible to hypothesize that these factors may affect psychophysical recovery by promoting the onset of depressive symptoms (detectable by the Symptom Questionnaire).

\section{Methods}

All subjects of this observational research completed an informed consent and received a description of the results of the test at the Hospital dismissing and at the control (SQ) and all the data have therefore been performed in accordance with the ethical standards laid down in the 1964 Declaration of Helsinki. Patient's anonymity was preserved and the obtained data were used exclusively for scientific purposes.

For this study, 25 subjects ( 23 males and 1 females) aged between 40 and 60 years (average age $56.4 \pm 3.9$ ) diagnosed with Acute Myocardial Infarction (AMI first episode), were consecutively examined.

The educational level was heterogeneous as showed below:

- 1 female and 10 male with High School diploma;

- 7 male with MA degree;

- 6 male and one female with MD or PhD.

All subjects were coming from the center - northern Italy and were resident in the same place from more than 10 years and more precisely in the regions of Emilia - Romagna, Lombardia, Toscana, Marche. The recruitment took place at the Santa Maria Nuova Hospital in Reggio Emilia in the period immediately following admission to the Coronary Intensive Care Unit (on average two to three days apart): the tests were expected to be administered only to those subjects who would subsequently be subjected to rehabilitation.

All patients willing to participate in the research underwent angioplasty surgery in the hours immediately following their entry into the ward; instead, they were interviewed in another Hospital, based in Castelnovo Ne' Monti (Northern Italian Apennines), where they were transferred to carry out rehabilitation therapy.

The clinical psychological assessment was carried out using the following tools:

Illness Behaviour questionnaire [27-29]: a 62-item self-report instrument that provides information relevant to the delineation of a patient's attitudes, ideas, affects, and attributions in relation to illness. It is interesting to note that the same authors [30] standardized it on infarcted patients (Table 1). 
Table 1. Mean (M) and standard deviation (SD) of the IBQ of the Adelaide infarcted patients

\begin{tabular}{|l|c|c|}
\hline \multirow{2}{*}{ Scales } & \multicolumn{2}{|c|}{ Test scores } \\
\cline { 2 - 3 } & $\mathrm{M}$ & $\mathrm{SD}$ \\
\hline General Hypochondriasis & 1.26 & 1.47 \\
\hline Disease Conviction & 1.54 & 1.52 \\
\hline Psychologic vs. Somatic perception of illness & 1.88 & 0.98 \\
\hline Affective Inhibition & 2.44 & 1.51 \\
\hline Affective Disturbances & 2.12 & 1.49 \\
\hline Denial & 3.38 & 1.51 \\
\hline Irritability & 1.58 & 1.53 \\
\hline
\end{tabular}

P Stress Questionnaire [10]: a questionnaire made up of 32 items grouped into six scales identified with factorial analysis [18]: Sense of Responsibility (Cronbach's $\alpha=0.70$ ), Vigor (Cronbach's $\alpha=0.59$ ), Stress Disorders (Cronbach's $\alpha=0.48$ ), Precision and Punctuality (Cronbach's $\alpha=0.61$ ), Spare Time (Cronbach's $\alpha=0.39$ ) and Hyperactivity (Cronbach's $\alpha=0.43$ ). It allows the detection of the presence of habits and lifestyles at risk for stress-related physical disorders attributable to some characteristics of the personality configuration known as "Type A". The stanine scores have a distribution between 1 and 9, with mean $=5$ and standard deviation $=1.96$ (Pruneti, 2011) [10];

Symptom Questionnaire [31,32]: a questionnaire of 92 items grouped into four scales indicating both pathological and well-being states; all items group four scales that evaluate symptoms such as Anxiety, Depression, Physical Symptoms and Hostility (cut off=4).

Cognitive Behavioural assessment $2.0[33,34]$ is a survey composed by seven sheets. First of all, the individual's clinical history, including the collection of data relating to the medical history of the subject and significant life events. There are also some standardized assessment scales: sheets 2 (STAI X-1) (20 items), 3 (STAI X-2) (20 items) and 10 (STAI X-3) (10 items) evaluate the subject's anxiety by taking the STAI-X test. Sheet 5 (EPQ/R) (48 items), the Eysenck Personality Questionnaire, assesses some stable personality dimensions such as introversion-extroversion, emotional stability, maladaptation and antisociality, simulation and social naiveté; sheet 6 (QPF/R) (30 items) provides the assessment of stress and psychophysiological disorders. Sheet 7 (IP) (58 items) assesses the subject's fears, taking up the Fear Survey Schedule, which clarifies the relationships between problem situations and emotional, cognitive and behavioral reactions. Sheet 8 (QD) (24 items) assesses any depressive symptoms thanks to Questionnaire D. Sheet 9 (MOCQ/R) (21 items), finally, analyzes the subject's obsessions and compulsions through the Maudsley Obsessional-Compulsive Questionnaire. A score equal to or greater than the 70th percentile is considered clinically significant [34]. The reliability and validity of the test are documented in the original manual [33]. Test-retest reliability ranges from 0.72 and 0.85 (seven days), and from 0.61 and 0.89 (30 days). Cronbach's alpha ranges from 0.74 and 0.92 (community), and from 0.68 and 0.97 (patients), except for the $\mathrm{P}$ Scale of the Eysenck Personality Questionnaire (0.32).

As already mentioned, the first meeting with the patients took place during the ICU hospitalization, which obviously influenced the choice of easily compiled psychological instruments that did not require excessive mental effort.

It is easy to imagine that a structured interview or an overly invasive assessment is not advisable in the "warm phase" of illness, and this is why it was decided here to administer the three shorter tests.

The tests were presented (in this order: Symptom Questionnaire, Illness Behavior Questionnaire and P Stress Questionnaire) to the patient's bedside, respecting his condition as a person already suffering and worried.

Ten days later, in the Hospital of Castelnuovo ne 'Monti, home of the cardiac rehabilitation, the second meeting was held in which the compilation of the CBA battery and the second administration of the Symptom Questionnaire were requested.

A qualified operator took care of guiding the compilation of the CBA battery by transcribing the answers given by the patient, as this test is in-depth, long and detailed.

This "setting" condition, very similar to the first interview experience, facilitated the establishment of human contact with the participants in the research.

\section{Results}

For all the scores obtained at the various psychological tests, the average values and the standard deviations were calculated.

Because of the relatively low number of subjects, in the descriptive analysis it was important to understand the homogeneity and representativeness of the selected sample by comparing the values found with the normative indices obtained from the standardization of tests administered on other populations of infarcts.

The application of Student's t-test for repeated measures between the two consecutive administrations of the SQ served to understand if significant changes were present in the transition from ICU to rehabilitation for some of the scores obtained at the various scales.

The Bravais-Pearson correlation coefficient was calculated to search for characteristic associations between the variables of the tests, as well as typical response patterns that include psychological, behavioral and symptomatology aspects associated with lifestyle, personality traits and any presence of psychopathological syndromes.

Given the significant amount of the correlations found, factor analysis was also used in an attempt to insert, label and reunite the variables into significant groupings in search of additional elements that united the subjects beyond the diagnosis of AMI.

The analysis of the descriptive statistics made it possible to understand, albeit inductively, both the real homogeneity of the sample and the usefulness and the functionality of the procedure used in order to highlight and describe "typical response configurations".

To analyze the average values reported by the sample to the CBA assessment battery, a comparison between the results obtained and those described by the authors will be made. The standardization was carried out on somatic patients (mostly suffering from ischemic heart disease) hospitalized for rehabilitation treatment [33,35]. For interpretative needs, it was necessary to go back to the percentile ranks of the relative averages in the 25 scales of which the battery is made up.

The sample shows medium scores (around the $50^{\text {th }}$ percentile) on the scales that evaluate trait anxiety and state anxiety (Table 2 ). The assessment at the start and at the completion of the test (STAI-X1, STAI-X2, STAI-X1/R) had shown that the moderate value of the state anxiety was a little grower at the end of the test administration (60.9 vs. 64.4).

In table 2, in bold the scores resulted higher and significant (is accepted significant a value higher than the third interquartile interval or with equal to the $70^{\text {th }}$ percentile or more). 
Table 2. Average, standard deviation and percentile ranks of the CBA battery

\begin{tabular}{|c|c|c|c|}
\hline \multirow{2}{*}{ Subscales } & \multicolumn{3}{|c|}{ Test scores } \\
\hline & $\mathrm{M}$ & $\mathrm{SD}$ & PERCENTILE \\
\hline STAI-X1 & 37.2 & 9.79 & 60.9 \\
\hline STAI-X2 & 37.4 & 8.01 & 50.4 \\
\hline EPQ/R-E & 8.2 & 3.46 & 47.1 \\
\hline EPQ/R-N & 4.44 & 3.45 & 46.4 \\
\hline EPQ/R-P & 3.04 & 1.81 & 64.3 \\
\hline EPQ/R-L & 9.28 & 1.79 & 54.1 \\
\hline QPF-R & 43.56 & 8.75 & 77.2 \\
\hline IP/F & 62.04 & 22.6 & 58.8 \\
\hline $\mathrm{IP} / \mathrm{PH}$ & 4 & 3.34 & 86.2 \\
\hline $\mathrm{IP} / 1$ & 16.84 & 6.32 & 57.5 \\
\hline $\mathrm{IP} / 2$ & 22.2 & 7.4 & 58.7 \\
\hline $\mathrm{IP} / 3$ & 7.44 & 5.34 & 62.6 \\
\hline $\mathrm{IP} / 4$ & 4.68 & 4.97 & 73.2 \\
\hline $\mathrm{IP} / 5$ & 6.24 & 4.7 & 47.7 \\
\hline QD & 5.52 & 4.42 & 86.6 \\
\hline MOCQ/R & 5.16 & 4.23 & 43.2 \\
\hline MOCQ/R1 & 3.12 & 2.62 & 57 \\
\hline MOCQ/R2 & 1.84 & 2.1 & 44.4 \\
\hline MOCQ/R3 & 0.48 & 0.71 & 24.6 \\
\hline STAI-X1R & 15.52 & 4.59 & 64.4 \\
\hline STAI DIFF & -2.04 & 3.65 & 33.6 \\
\hline STAI ACC & 0.8 & 1.91 & 33 \\
\hline IR INDEX & 5.08 & 1 & 24.3 \\
\hline
\end{tabular}

Note: STAI-X1=Stait-Trait Anxiety Inventory X-1: State anxiety before the test; STAI$\mathrm{X} 2=$ Stait-Trait Anxiety Inventory X-2: Trait Anxiety; EPQ/R-E=Eysenck Personality Inventory: Extroversion (E); EPQ/R-N=Eysenck Personality Inventory: Neuroticism (N); EPQ/R-P=Eysenck Personality Inventory: Psychoticism (P); EPQ/R-L=Eysenck Personality Inventory Simulation/Social ingenuity (L); QPF-R=Psychophysiological Questionnaire: Psychophysiological Disorders; IP/F=Inventory of fears: Phobias; IP/ $\mathrm{PH}=$ Inventory of fears: Answers "very much fear"; IP/1 = Inventory of fears: CalamityDangers; IP/2=Inventory of fears: Social Events; IP/3=Inventory of fears: Repellent animals; IP/4=Inventory of fears: Separation; IP/5=Inventory of fears: Blood/Wounds; $\mathrm{QD}=\mathrm{D}$ questionnaire: Depressive manifestations; $\mathrm{MOCQ} / \mathrm{R}=$ Maudsley Obsessive Compulsive Questionnaire: Obsessions-Compulsions; MOCQ/R1=Maudsley Obsessive Compulsive Questionnaire: Control; MOCQ/R2=Maudsley Obsessive Compulsive Questionnaire: Cleaning; MOCQ/R3=Maudsley Obsessive Compulsive Questionnaire: Doubt; STAI-X1R=Stait-Trait Anxiety Inventory X-1/R: State anxiety after the test; STAI DIFF=Stait-Trait Anxiety Inventory: Anxiety comparison before-after the test; STA ACC=Accuracy in compilation; IR INDEX $=$ Coherence.

Is evident a fear and phobic reaction to the illness state with a Wolpe's Fear Inventory PH subscale=86.2. It is also significant the score obtained at the same questionnaire of the CBA that the subscale that evaluate the fear to remain alone.

One interesting mean value is the score obtained at the psychophysiological (psychosomatic) manifestation (73.2) surely influenced by the illness state. At the last but not at least, one wellknown data confirmed in the present study. Depression manifestation had the higher score of the CBA battery test (86.6 percentiles).

As showed in Table 3, the average scores obtained in the P Stress Questionnaire [10] are all relatively high (cut-off=5). It is important to note that the high scores in the factors measured by the instrument in question reveal the presence of dysfunctional behavior in the area of interest investigated. Therefore, of particular attention is the tendency to have a hectic pace of life denounced by a particularly high value to the Hyperarousal factor (mean=5.48 \pm 1.90 ; stanine=6) and to appear excessively energetic and vital to the Vigor (mean $=4.6 \pm 2.58$; stanine $=8$ ). Moreover, all these scores are significant with the marked vulnerability to stress shown by the subjects of the sample (mean $=3.72$ \pm 1.86 ; stanine $=4$ ).
For all the scales of the Symptom Questionnaire, scores are detected above the threshold both in the first (Table 4) and in the second administration (Table 5).

Comparing the average values of the Illness Behaviour Questionnaire of the sample with those obtained from the Adelaide infarcted patients [30] several similarities emerge (Table 6). The highest average score achieved in both cases is that of denial of illness.

In fact, the average of the normative sample is $3.38 \pm 1.51$ (table 1) while the average obtained from the infarcted people of Reggio Emilia is $3.16 \pm 1.57$.

Student's t-test for dependent samples to compare the average values obtained at the two administrations of the Symptom Questionnaire, which allowed highlighting a significant decrease in the Hostility parameter during the rehabilitation phase (Tables 7 and 8).

The following correlations were significant by calculating the Bravais-Pearson coefficient $r$ :

Table 3. Average, standard deviation, stanine standard scores and cut-off of the sub scales of the PSQ

\begin{tabular}{|l|c|c|c|c|}
\hline \multirow{2}{*}{ Scales } & \multicolumn{4}{|c|}{ Test scores } \\
\cline { 2 - 5 } & $\mathrm{M}$ & $\mathrm{SD}$ & STANINE & CUT-OFF \\
\hline Sense of Responsibility & 7.92 & 2.2 & 6 & 5 \\
\hline Vigor & 4.6 & 2.58 & 8 & 5 \\
\hline Stress-related disorders & 3.72 & 1.86 & 4 & 5 \\
\hline Precision and Punctuality & 4.76 & 1.88 & 6 & 5 \\
\hline Spare Time & 2.96 & 1.88 & 7 & 5 \\
\hline Hyperactivity & 5.48 & 1.9 & 6 & 5 \\
\hline TOT & 33.48 & 6.39 & 7 & \\
\hline
\end{tabular}

Table 4. Mean and standard deviation for the first administration of the Symptom Questionnaire

\begin{tabular}{|c|c|c|c|}
\hline \multirow{2}{*}{ Scales } & \multicolumn{3}{|c|}{ Test scores } \\
\cline { 2 - 4 } & MEAN & SD & CUT-OFF \\
\hline A & 6.88 & 5.46 & 4 \\
\hline D & 6.64 & 4.37 & 4 \\
\hline S & 8.08 & 6.1 & 4 \\
\hline H & 5.04 & 3.99 & 4 \\
\hline
\end{tabular}

Note: $\mathrm{A}=$ Anxiety ( $1^{\text {st }}$ administration); $\mathrm{D}=$ Depressive symptoms $\left(1^{\text {st }}\right.$ administration); $\mathrm{S}=$ Somatic complaints $\left(1^{\text {st }}\right.$ administration); $\mathrm{H}=$ Hostility $\left(1^{\text {st }}\right.$ administration $)$.

Table 5. Mean and standard deviation for the second administration of the Symptom Questionnaire

\begin{tabular}{|c|c|c|c|}
\hline \multirow{2}{*}{ Scales } & \multicolumn{3}{|c|}{ Test scores } \\
\cline { 2 - 4 } & MEAN & SD & CUT-OFF \\
\hline A1 & 6.64 & 5.27 & 4 \\
\hline D1 & 7.56 & 3.64 & 4 \\
\hline S1 & 7.64 & 5.57 & 4 \\
\hline H1 & 3 & 3.2 & 4 \\
\hline
\end{tabular}

Note: A1=Anxiety ( $2^{\text {nd }}$ administration $) ; D 1=$ Depressive symptoms ( $2^{\text {nd }}$ administration $)$; $\mathrm{S} 1=$ Somatic complaints $\left(2^{\text {nd }}\right.$ administration $) ; \mathrm{H} 1=$ Hostility $\left(2^{\text {nd }}\right.$ administration $)$.

Table 6. Mean and standard deviation of IBQ Scales

\begin{tabular}{|l|c|c|}
\hline \multirow{2}{*}{ Scales } & \multicolumn{2}{|c|}{ Test scores } \\
\cline { 2 - 3 } & $\mathrm{M}$ & $\mathrm{SD}$ \\
\hline General Hypochondriasis & 2.76 & 1.67 \\
\hline Disease Conviction & 2.2 & 1.83 \\
\hline Psychologic vs. Somatic perception of illness & 2.04 & 0.98 \\
\hline Affective Inhibition & 2.52 & 1.36 \\
\hline Affective Disturbances & 1.88 & 1.67 \\
\hline Denial & 3.16 & 1.57 \\
\hline Irritability & 1.2 & 1.12 \\
\hline
\end{tabular}


Table 7. T value and relative significance between the first and the second administration of the SQ

\begin{tabular}{|c|c|c|}
\hline Scales & \multicolumn{2}{|c}{ Values } \\
\cline { 2 - 3 } & $\mathrm{t}$ & \\
\hline $\mathrm{A}-\mathrm{A} 1$ & 0.226 & 0.82 \\
\hline $\mathrm{D}-\mathrm{D} 1$ & -1.31 & 0.20 \\
\hline $\mathrm{S}-\mathrm{S} 1$ & 0.466 & 0.65 \\
\hline $\mathrm{H}-\mathrm{H} 1$ & 2.137 & $0.029 *$ \\
\hline
\end{tabular}

Note: A=Anxiety ( $1^{\text {st }}$ administration $)$; $\mathrm{D}=$ Depressive symptoms ( $1^{\text {st }}$ administration); $\mathrm{S}=$ Somatic complaints $\left(1^{\text {st }}\right.$ administration $) ; \mathrm{H}=$ Hostility $\left(1^{\text {st }}\right.$ administration); A1=Anxiety $\left(2^{\text {nd }}\right.$ administration); $\mathrm{D} 1=$ Depressive symptoms ( $2^{\text {nd }}$ administration $)$; S1=Somatic complaints ( $2^{\text {nd }}$ administration $)$; H1=Hostility $\left(2^{\text {nd }}\right.$ administration). * *significant differences.

Table 8. Significant coefficients $r$ between the various scales and subscales of the CBA Battery

\begin{tabular}{|c|c|c|c|c|c|c|c|c|}
\hline \multirow{2}{*}{ Subscales } & \multicolumn{8}{|c|}{ Correlations } \\
\hline & STAI-X1 & STAI-X2 & EPQ/ R-N & QPF-R & MOCQ/R & $\mathrm{MOCQ} / \mathrm{R} 1$ & $\mathrm{MOCQ} / \mathrm{R} 2$ & MOCQ/R3 \\
\hline EPQ RN & $0.64 * *$ & $0.71^{* *}$ & N.S. & $0.41 *$ & N.S. & N.S. & N.S. & $0.50^{*}$ \\
\hline QPFR & $0.43^{*}$ & $0.40^{*}$ & $0.41^{*}$ & N.S. & N.S. & N.S. & N.S. & N.S. \\
\hline $\mathrm{IP} / \mathrm{F}$ & $0.45^{*}$ & $0.54 * *$ & $0.58 * *$ & N.S. & $0.48 *$ & N.S. & $0.40 *$ & $0.55^{* *}$ \\
\hline $\mathrm{IP} / \mathrm{PH}$ & N.S. & $0.42 *$ & N.S. & N.S. & N.S. & N.S. & N.S. & N.S. \\
\hline IP/1 & N.S. & $0.43^{*}$ & $0.40 *$ & N.S. & $0.58 * *$ & $0.43^{*}$ & $0.55 * *$ & $0.49 *$ \\
\hline $\mathrm{IP} / 2$ & N.S. & $0.43^{*}$ & $0.41 *$ & N.S. & N.S. & N.S. & N.S. & N.S. \\
\hline $\mathrm{IP} / 3$ & $0.55 * *$ & N.S. & N.S. & N.S. & N.S. & N.S. & N.S. & N.S. \\
\hline $\mathrm{IP} / 4$ & N.S. & N.S. & $0.46^{*}$ & $0.62 * *$ & $0.64 * *$ & $0.54 * *$ & $0.51 * *$ & $0.69 * *$ \\
\hline $\mathrm{IP} / 5$ & $0.55 * *$ & $0.43^{*}$ & $0.41 *$ & N.S. & N.S. & N.S. & N.S. & $0.48^{*}$ \\
\hline QD & $0.71 * *$ & $0.67 * *$ & $0.64 * *$ & $0.53 * *$ & N.S. & N.S. & N.S. & N.S. \\
\hline
\end{tabular}

Note: STAI-X1=Stait-Trait Anxiety Inventory X-1: State anxiety before the test; STAI-X2=Stait-Trait Anxiety Inventory X-2: Trait Anxiety; EPQ/R-N=Eysenck Personality Inventory: Neuroticism (N); QPF- R=Psychophysiological Questionnaire: Psychophysiological Disorders; IP/F=Inventory of fears: Phobias; IP/PH=Inventory of fears: Answers "very much fear"; IP/1=Inventory of fears: Calamity-Dangers; IP/2=Inventory of fears: Social Events; IP/3=Inventory of fears: Repellent animals; IP/4=Inventory of fears: Separation; IP/5=Inventory of fears: Blood/Wounds; QD=D questionnaire: Depressive manifestations; MOCQ/R=Maudsley Obsessive Compulsive Questionnaire: Obsessions-Compulsions; MOCQ/R1=Maudsley Obsessive Compulsive Questionnaire: Control; MOCQ/R2=Maudsley Obsessive Compulsive Questionnaire: Cleaning; MOCQ/R3=Maudsley Obsessive Compulsive Questionnaire: Doubt. P Values: $* *<0.05 ; *<0.01$

Table 9. Significant coefficients $r$ between the various scales and sub scales of the CBA battery, the PSQ factor scales and the SQ symptomatology scales

\begin{tabular}{|c|c|c|c|c|c|c|c|c|c|}
\hline & & \multicolumn{8}{|c|}{ Correlations } \\
\hline & & \multicolumn{4}{|c|}{ PSQ } & \multicolumn{4}{|c|}{ SQ } \\
\hline & & SR & V & DS & TOT & $\mathrm{A}$ & $\mathrm{D}$ & S & $\mathrm{O}$ \\
\hline \multirow{2}{*}{ STAI } & $\mathrm{X} 1$ & N.S. & N.S. & $0.67^{* *}$ & N.S. & $0.72 * *$ & $0.62 * *$ & $0.50^{* *}$ & N.S. \\
\hline & $\mathrm{X} 2$ & N.S. & N.S. & $0.57 * *$ & N.S. & $0.55^{* *}$ & $0.53^{* *}$ & N.S. & $0.52 * *$ \\
\hline \multirow{2}{*}{ EPQ } & R-E & N.S. & $0.41^{*}$ & N.S. & N.S. & N.S. & N.S. & N.S. & N.S. \\
\hline & R-N & $0.49 *$ & N.S. & $0.52 * *$ & N.S. & $0.57^{* *}$ & $0.51^{* *}$ & N.S. & N.S. \\
\hline \multirow{7}{*}{ IP-R } & $\mathrm{IP} / \mathrm{F}$ & N.S. & N.S. & $0.43^{*}$ & N.S. & $0.58^{* *}$ & $0.57 * *$ & N.S. & N.S. \\
\hline & $\mathrm{IP} / \mathrm{PH}$ & N.S. & N.S. & N.S. & $0.40^{*}$ & N.S. & N.S. & N.S. & N.S. \\
\hline & $\mathrm{IP} / 1$ & N.S. & $0.42 *$ & N.S. & $0.42 *$ & N.S. & N.S. & N.S. & $0.46^{*}$ \\
\hline & $\mathrm{IP} / 3$ & N.S. & N.S & N.S. & N.S. & $0.50^{* *}$ & $0.49^{*}$ & N.S. & N.S. \\
\hline & $\mathrm{IP} / 4$ & N.S. & N.S. & N.S. & N.S. & $0.58^{* *}$ & $0.54 * *$ & N.S. & N.S. \\
\hline & $\mathrm{IP} / 5$ & N.S. & N.S. & N.S. & N.S. & $0.51^{* *}$ & $0.47^{*}$ & N.S. & N.S. \\
\hline & QD & N.S. & N.S. & $0.62 * *$ & N.S. & $0.61^{* *}$ & $0.53^{* *}$ & N.S & $0.47 *$ \\
\hline MOCQ & $\mathrm{R} 2$ & N.S. & $0.42 *$ & N.S. & $0.47^{*}$ & $0.39^{*}$ & N.S. & N.S. & N.S. \\
\hline
\end{tabular}

Note: CBA Battery: STAI-X1=Stait-Trait Anxiety Inventory X-1: State anxiety before the test; STAI-X2=Stait-Trait Anxiety Inventory X-2: Trait Anxiety; EPQ/R-N=Eysenck Personality Inventory: Neuroticism (N); EPQ/R-E=Eysenck Personality Inventory: Extroversion (E); IP/F=Inventory of fears: Phobias; IP/PH=Inventory of fears: Answers "very much fear"; IP/1=Inventory of fears: Calamity-Dangers; IP/3=Inventory of fears: Repellent animals; IP/4=Inventory of fears: Separation; IP/5=Inventory of fears: Blood/Wounds; QD=D questionnaire: Depressive manifestations; MOCQ/R2=Maudsley Obsessive Compulsive Questionnaire: Cleaning. PSQ: SR=Sense of Responsibility; V=Vigor; DS=Stress-related disturb. SQ: A=Anxiety; D=Depression; S=Somatic Symptoms; H=Hostility.

P Values:**<0.05; $*<0.01$.

As showed in Table 9, regarding the PSQ factorial evaluation scales in association with the CBA battery scale scores, significant correlations emerge between the Sense of Responsibility and the EPI neuroticism scale. The scores obtained at the factorial scale Vigor, which represents the perception that the subject has of himself, have a similar trend to the scores of the Extroversion scale and the MOCQ scale that detects the tendency to obsession with cleanliness.

The Stress Disorders scale of PSQ correlates with the levels of anxiety, of both state and trait, highlighting the sensitivity to stress also from an autonomic point of view. One more correlation is with the
Neuroticism scale, thus describing the scarce emotional self-regulation skills necessary to the recovery of psychophysical balance, and with the symptoms of depression.

Regarding the Symptom Questionnaire scales, the scores of the Anxiety scale have a trend similar to the trait and state anxiety emerged from the CBA battery, correlates with the neuroticism of the EPI and with some scales of the Inventory of Fears of the same battery.

The symptoms of Depression correlate with both of state and trait anxiety and with those of the neuroticism scale, highlighting a particular sensitivity to stressful events, which tend to be perceived as 
threatening and dangerous and following which the subject struggles to recover emotional balance.

The scores on the Somatic Symptoms scale of SQ correlate with those of state anxiety, confirming the psychological tension that characterizes the clinical condition of this group of patients.

Finally, Hostility appears to correlate with both trait anxiety and depression. That data could highlight the general propensity of these subjects to experiment high levels of emotional intensity, in particular unpleasantness such as hostility and anger not necessarily manifested.

\section{Discussion}

This study had the objective of evaluating the existence and consistency of psychological aspects, behavioral modalities or lifestyles capable of uniting a population of patients diagnosed with AMI, in order to identify adverse knowledge and attitudes to health, to evaluate the impact of psychological variables and their interaction with biological ones.

The choice of psychological assessment material to be used was considered in an attempt to observe the intertwining of different dimensions in the psychological and behavioral field.

The area of distress symptoms was assessed with the double administration of the Symptom Questionnaire. The Illness Behavior Questionnaire has been used to reveal some of the most typical reactions to the state of illness. The CBA Battery has served to describe the type of personality and to highlight further psychopathological tendencies. Then, the P Stress Questionnaire allowed a survey on the stress-related lifestyle, habits and behavior of patients. Despite the small number of subjects recruited, a significant adherence of some important scales to the normative values was noted; moreover, even on those scales where the values are lower or higher than in the population of comparison, a tendency to assume similar polarity can be observed. This supports the idea that this psychological test is largely suitable for the evaluation of subjects after a first episode of AMI.

Just from the descriptive statistics, it is possible to draw some considerations.

The average of the scores obtained by the sample at the Beck Depression Inventory of the CBA2.0 reveals a marked tendency of the infarcted subjects to present a depressive symptomatology. This data is in line with what was found by the authors of the manual of the same test [33]. The SQ depression parameter was equally high and this is true for the other scales measured by the instrument: Anxiety, Somatic Symptoms and Hostility. The presence of this symptomatology may depend on the condition of hospitalization, on the feeling of loneliness and abandonment, or reflect more stable conditions of the subjects worsened by the particular state of illness.

However, the application of Student's t-test showed a significant decrease in the value referred to hostility in the second administration: the link between this factor and the pathologies affecting the cardiovascular system has long been denounced by countless studies on the argument. We briefly recall in this regard the studies of Friedman, et al. [36,37] which, together with the psychologist Jenkins first described the "Type A behavior".

This expression later went on to denote personalities vulnerable to stress and at risk of heart disease precisely because they are excessively competitive, victims of the "time urgency", impatient and acrimonious [10,11,38-41]. Furthermore, the similar trend between the factorial scale Vigor of the PSQ, the scores of the Extroversion scale and the MOCQ of the CBA Battery could be mean that these people are characterized by the tendency of searching the perfection, which is obsessively chased because it is supported by the belief of having high levels of energy available.

Finally, the significant correlations emerged between the Sense of Responsibility and the EPI neuroticism scale could highlight the tendency of the subjects under examination to assume excessive responsibility that leads to loss of emotional balance.

A study by Smith, et al. [5] highlights as the issue of control is crucial, claiming to be able to summarize the conception of the disease of this type of patient with the sentence: "I was in control of it at the start". This well describes the trend to control, which characterizes these patients, with the tendency to an extreme precision and indulging an excessive sense of responsibility [18].

In light of these considerations, it is easy to ask what is more uncontrollable than a heart attack. Being suddenly struck by such a serious pathology, finding himself suddenly occupying a hospital bed. The real possibility to dead, touching with hand the feeling of helplessness that arose from having lost contact with supposed certainties and with the body, feeling at the mercy of events. Furthermore, depending on others and knowing that one's destiny lies in the hands, even if competent, of healthcare professionals who are, however, complete strangers, offers an adequate interpretation of the state of these subjects. Jensen, et al. [42] and Hutton, et al. [43] argue that the feeling most frequently described by this type of patients is the sense of shock and uncertainty, about the disease but also towards the treatment. Furthermore, Astin, et al. [2] described an alteration in the sense of self-described by these patients, who experience a feeling of loss and helplessness, most likely attributable to the functional limitations that characterize the period of convalescence.

Seligman [44], in his studies on learned helplessness, argues that one of the main symptoms of depression in patients originates from the inability to predict the situation and to be able to attribute themself an important role in it [45]. Learned helplessness is linked to cognitive attributions, which can be specific/global, internal/external and stable/unstable $[46,47]$. Global attribution implies the belief that negative event is contextually consistent rather than specific to a particular circumstance. Internal attribution is related to the belief that the adverse situation occurs due to individual factor, behaviors or conditions rather than external circumstances; stable attribution is the belief that the adverse situation is immutable over time [48]. People constitutionally predisposed to depression attribute negative events to internal, stable and global factors, favoring the onset of learned helplessness $[46,49]$.

Nevertheless, how is it possible that the score above the threshold obtained at the hostility parameter of the same test returns to normal within a few days of the heart attack?

It seems reckless to think that after such a short time patient have objectively regained control over their life, feeling again masters of their own health and able to provide for their own well-being. It is probably more correct and realistic to hypothesize that feeling less acrimonious depends on having received some more clarification regarding the disease, on being reassured about what can be continued once left the hospital. In fact, during the second meeting, many patients appeared full of good intentions declaring that they wanted to quit smoking, that they had decided to work a little less and had to eat better; they also attributed the cause of their illness to some of these factors. In support 
of this idea, Glass, et al. [50] showed that the exercise of control is not crucial, but the belief that you can have it is [45]. Tracking down potential causes and thinking about possible remedies can have a sedative effect. The decrease in hostility during rehabilitation could be attributed to the greater awareness of their state of health: in fact, at the interview carried out there, the patients were better informed about the disease that had affected them, reassured by having received detailed clinical information from the doctors and the healthcare professionals. In fact, in the aforementioned study by Smith, et al. [5], participants reported that they were in control of their recovery; they were also aware that their actions and lifestyle would have an impact on future disease risk [5].

In fact, cardiovascular rehabilitation requires that patients do a little physical activity, follow a diet and take walks in the open air, thus getting used to conducting a healthier lifestyle.

The high values reported to the various factors measured by the P Stress Questionnaire also show that the subjects had adopted dysfunctional, maladaptive and inadequate attitudes and habits for a long time in the past. The majority of the lifestyles are characterized by an excessive sense of responsibility, by extreme need of doing everything by yourself without delegating, in the spasmodic search for the maximum precision and punctuality at the cost of never having time for yourself to do something pleasant.

In addition, it should be noted that a particular vulnerability to stress (particularly high stress disorder factor) emerged; furthermore, it shows significant correlations with these parameters: Anxiety, Depression, Somatic Symptoms and Hostility of the SQ (Table. 9).

The average value relating to the negation is the highest among those measured by the IBQ and "this is one of the most characteristic signs of the infarcted patients even if not exclusive" [18].

Then, it is important to point out that the total average score obtained at the PSQ (mean=33.48) is perfectly in line with the value reported by a much larger experimental group recruited for the standardization of the same instrument (mean $=32.81$, in 600 subjects). This is a further guarantee of the representativeness of the sample and of similar way in conducting their existence by these patients.

In addition, in the field of research that explores post-heart attack reactions and adaptations, also a line investigates positive adaptation to various disease. For example, Pinquart, et al. [4], found that patients undergoing treatment for cancer achieved benefits in terms of psychological well-being, reporting to have enhanced social support. Furthermore, in patients with spinal cord injuries there was an improvement both at the social level and at the individual level with the definition of life goals and the increase in the ability to accept external events [51]. Similarly, growth has also been shown in numerous studies on infarcted patients. For example, Hildingh, et al. [52] described a frequent reorganization of the life according to new values; a development in the motivation for change was also observed, aimed at seeking a balance with himself and others. In addition, Hutton, et al. [43] described a positive post-heart attack growth: patients in this study reported that they felt healthier following post-cardiac rehabilitation and that they had used social resources to reflect on their clinical condition [5].

Furthermore, a sudden and unexpected event such as a heart attack forces the individual to focus attention on the present moment, on the so-called "here and now": this aspect is particularly delicate in a sample of cardiac patients characterized by hyperactivity, vigor and predisposed to the adoption of a lifestyle characterized by "time urgency". The empowerment of resources, aimed at favoring the ability to cope with a stressor of this type, can be supported by the CognitiveBehavioral techniques of third generation [53] such as Mindfulness, which is considered a real skill to improve. This construct is well represented by terms such as awareness and acceptance [9] and the purpose is to teach to pay attention to internal and external events and observe them for what they are, in a non-judgmental way.

Mindfulness, with Acceptance and Commitment, is one of the Acceptance and Commitment Therapy (ACT) techniques that are based on three fundamental points:

To learn to look at one's suffering and not to see the world through it.

To accept, to have a vital and conscious contact with one's own experience, aware of the fact that internal experiences are not the same as external events and that the methods to try to solve / eliminate them do not work.

Commit to take action in the direction of given values.

\section{Limitations}

The study was conducted on a smaller sample population with a disproportionate number of males and females. Hence, gender - wise comparisons could not be done and multivariate analysis could not be done. Despite this, it is interesting to note how subjects addressed to cardiovascular rehabilitation after an AMI episode, already have a relatively clear characterization of temperamental traits, lifestyles and risk behaviors, which should certainly be taken into serious consideration by clinicians.

\section{Conclusion and future line of research}

In the light of what described above, which moreover confirms what has been found in other similar studies, the rehabilitation of the cardiovascular patient must be multidisciplinary. In any case, it would be essential to assist it with a psychological intervention capable of reducing the impact of both the various stress-related factors but also of those predisposing at the temperamental and constitutional level that often aggravate the clinical picture of the infarcted. In fact, those dysfunctional behavioral patterns tend to perpetuate the risk of disease by emphasizing the damage that a maladaptive lifestyle has already brought, with the risk, moreover, of favoring recurrence. Therefore, it seems very appropriate to propose a global rehabilitative intervention capable of re-educating the patient to learn new strategies to cope with the problems that will arise, and thus mitigating the risk of relapse, and help him in achieving a good level of mental and physical well-being.

On this occasion, it is also possible to lay the foundations, together with all the healthcare staff, for learning how to manage a new and different lifestyle that, among other things, could promote compliance with therapeutic regimes and with limitations that often the event can produce.

\section{References}

1. Richards SH, Anderson L, Jenkinson CE, Whalley B, Rees K, et al. (2017) Psychological interventions for coronary heart disease. Cochrane Database Syst Rev 4: CD002902. [Crossref]

2. Astin F, Horrocks J, Closs SJ (2014) Managing lifestyle change to reduce coronary risk: A synthesis of qualitative research on peoples' experiences. BMC Cardiovascular Disorders 14: 96. [Crossref]

3. Prevedini AB, Presti G, Rabitti E, Miselli G, Moderato P (2011) Acceptance and commitment therapy (ACT): The foundation of the therapeutic model and an overview of its contribution to the treatment of patients with chronic physical diseases. G Ital Med Lav Ergon 33: 53-63. [Crossref] 
4. Pinquart M, Frohlich C, Silbereisen RK (2007) Cancer patients' perceptions of positive and negative illness-related changes. J Health Psychol 12: 907-921.

5. Smith F, Banwell E, Rakhit R (2016) 'I was in control of it from the start': A qualitative study of men's experiences of positive adjustment following a heart attack. $J$ Health Psychol 2017: 1345-1354. [Crossref]

6. Rosenhan DL (1973) On being sane in insane places. Science 179: 250-258.

7. Henoch I, Sawatzky R, Falk H, Fridh I, Jakobsson Ung E, et al. (2014) Symptom distress profiles in hospitalized patients in Sweden: a cross-sectional study. Res Nurs Health 37: 512-23.

8. Spatola CAM, Manzoni GM, Castelnuovo G, Malfatto G, Facchini M, et al. (2014) The ACTonHEART study: Rationale and design of a randomized controlled clinical trial comparing a brief intervention based on acceptance and commitment therapy to usual secondary prevention care of coronary heart disease. Health Qual Life Outcomes 12: 22. [Crossref]

9. Pruneti C (2016) Positive psychology: Old and new theoretical requirement for "living this moment". J Depress Anxiety 5: 242.

10. Pruneti C (2011) The P Stress Questionnaire: A new tool for the evaluation of stressrelated behaviors. Euro J of Clinical Psychology and Psychiatry 3: 1-37.

11. Friedman M (1977) Type "A" behavior pattern: some of its pathophysiological components. Bull N Y Acad Med 53: 593-604. [Crossref]

12. Rosenman RH (1991) Type A behavior pattern and coronary heart disease: The hostility factor? Stress Medicine 7: 245-253.

13. Pruneti C, Guccini I, Torelli P (2020) Psychophysiological features of primary headache: New findings and some confirmation. Arch Neurol Neurosci 8: 1-8.

14. Eaker ED, Sullivan LM, Kelly-Hayes M, D’Agostino RB, Benjamin EJ (2004) Anger and hostility predict the development of atrial fibrillation in men in the framingham offspring study. Circulation 109: 1267-1271. [Crossref]

15. Miličić D, Brajković L, Maček JL, Andrić A, Ardalić Z, et al. (2016) Type A personality, stress, anxiety and health locus of control in patients with acute myocardial infarction. Psychiatria Danubina 28: 409-414. [Crossref]

16. Pruneti C, Fontana F, Fante C, Carrozzo E (2010) Autonomic changes and stress responses in psychopathology. Euro J of Clinical Psychology and Psychiatry 3: 1-20.

17. Williams RB (2001) Hostility: Effects on health and the potential for successful behavioral approaches to prevention and treatment. In: Baum A, Revenson TA (Eds): Hand-book of Health Psychology. Mahwah, NJ: Erlbaum.

18. Bonaguidi F, Michelassi C, Trivella MG, Carpeggiani C, Pruneti CA, et al. (1996) Cattel's 16 PF and Psy Inventory: Relationship between personality traits and behavioral responses in patients with acute myocardial infarction. Psychol Rep 78: 691-702. [Crossref]

19. Pruneti C, Giusti M, Boem M, Luisi M (2002) Behavioral, psycho-physiological and salivary cortisol modifications after short-term alprazolam treatment in patients with recent myocardial infarction. Ital Heart J 3: 53-59.

20. Vaccarino V, Krumholz HM, Yarzebski J, Gore JM, Goldberg RJ (2001) Sex differences in 2 year mortality after hospital discharge for myocardial infarction. Ann Intern Med 169: 1767-1774. [Crossref]

21. Barth J, Schumacher M, Herrmann-Lingen C (2004) Depression as a risk factor for mortality in patients with coronary heart disease: a meta-analysis. Psychosom Med 66 802-813. [Crossref]

22. Worcester MU, Goble AJ, Elliott PC, Froelicher ES, Murphy BM, et al. (2019) Mild depression predicts long-term mortality after acute myocardial infarction: A 25-Year Follow-Up. Heart Lung Circ 28: 1812-1818. [Crossref]

23. Musselman DL, Evans DL, Nemeroff CB (1998) The relationship of depression to cardiovascular disease. Arch Gen Psychiatry 55: 580-592. [Crossref]

24. Kiecolt-Glaser JK, Glaser R (2002) Depression and immune function: central pathways to morbidity and mortality. J Psychosom Res 53: 873-876. [Crossref]

25. Appels A, Bär FW, Bär J, Bruggeman C, De Beats M (2000) Inflammation, depressive symptomatology, and coronary artery disease. Psychosom Med 62: 601-605. [Crossref]

26. Danesh J, Whincup P, Walker M, Lennon L, Thomson A, et al. (2000) Low grade inflammation and coronary heart disease: prospective study and update meta-analyses. BMJ 321: 199-203. [Crossref]

27. Pilowsky I, Spence ND (1975) Patterns of illness behaviour with intractable pain. $J$ Psychosom Res 19: 279-287.

28. Pilowsky I, Spence ND (1994) Manual for the illness behavior questionnaire (IBQ), (3rd Edn). Adelaide: University of Adelaide.
29. Fava GA, Bernardi M, Pilowsky I, Spence ND (1982) Versione italiana dell'Illness Behaviour Questionnaire (IBQ) di Pilowsky e Spence. In: Canestrari R (Ed), Nuovi metodi in psicometria. Firenze: Organizzazioni Speciali.

30. Pilowsky I, Chapman CR, Bonica JJ (1977) Pain, depression, and illness behavior in a pain clinic population. Pain 4: 183-192. [Crossref]

31. Fava R (1976) Abridged manual of the Symptom Questionnaire. Albuquerque: University of New Mexico.

32. Fava GA, Kellner R, Perini GI, Michelacci L, Munari F, et al. (1983) Italian validation of the symptom rating test (SRT) and symptom questionnaire (SQ). Can J Psychiatry 28: 117-123. [Crossref]

33. Sanavio E, Bertolotti G, Michielin P, Vidotto G, Zotti AM (1986) CBA-2.0 Scale Primarie: Manuale: Una batteria a largo spettro per l'assessment psicologico. Firenze, Organizzazioni Speciali, Italy.

34. Sanavio E (1997) CBA 2.0: cognitive behavioural assessment 2.0: scale primarie: manuale. Firenze: Organizzazioni speciali.

35. Sanavio E (2002) Le Scale CBA. Cognitive Behavioural Assessment: un modello di indagine psicologica multidimensionale. Milano: Raffaello Cortina Editore.

36. Friedman M, Rosenman RH (1959) Association of specific overt behavior pattern with blood and cardiovascular findings: blood cholesterol level, blood clotting time, incidence of arcus senilis and clinical coronary artery disease. JAMA 169: 1286-1296. [Crossref]

37. Friedman M, Rosenman RH (1974) Neurogenic factors in pathogenesis of coronary heart disease. Med Clin North Am 58: 269-279. [Crossref]

38. Friedman M (1969) Pathogenesis of coronary heart disease. McGraw Hill, New York.

39. Friedman M, Thoresen CE, Gill JJ, Urmer D, Thomson L, et al. (1982) Feasibility of altering type A behavior pattern after myocardial infarction. Circulation 66: 83-92. [Crossref]

40. Friedman M, Ulmer D (1984) Treating type A behavior and your heart. Fawcett Crest, New York.

41. Friedman M, Thoresen C, Gill J (1986) Alteration of Type A behavior and its effect on cardiac recurrences in post-myocardial infarction patients: Summery results of the recurrent coronary prevention project. Am Heart J 112: 653-665. [Crossref]

42. Jensen OB, Petersson K (2003) The illness experiences of patients after a first time myocardial infarction. Patient Educ Couns 51: 123-131. [Crossref]

43. Hutton J, Perkins S (2008) A qualitative study of men's experience of myocardial infarction. Psychol Health Med 13: 87-97. [Crossref]

44. Seligman MEP (1975) Helplessness: On Depression, Development, and Death. WH Freeman, San Francisco.

45. Sapolsky RM (1992) Is this relevant to the human? In: Stress, the aging brain and the mechanisms of neuron death, Cambridge, MA: MIT pp: 305-339.

46. Abramson LY, Seligman MEP, Teasdale JD (1978) Learned helplessness in humans: Critique and reformulation. J Abnorm Psychol 87: 49-74. [Crossref]

47. Hiroto DS, Seligman MEP (1975) Generality of learned helplessness in man. J Pers Soc Psychol 31: 311-327.

48. Miller WR, Seligman ME (1975) Depression and learned helplessness in man. $J$ Abnorm Psychol 84: 228-238. [Crossref]

49. Peterson C, Maier SF, Seligman ME (1993) Learned helplessness. A theory for the age of personal control. Oxford University Press, New York.

50. Glass D, Singer J (1972) Urban stress: Experiments on noise and social stressor Academy Press, New York.

51. Dibb B, Ellis-Hill C, Donovan-Hall M, Burridge J, Rushton D, et al. (2014) Exploring positive adjustment in people with spinal cord injury. J Health Psychol 19: 1043-1054.

52. Hildingh C, Fridlund B, Lidell E (2006) Access to the world after myocardial infarction: Experiences of the recovery process. Rehabil Nurs 31: 63-68. [Crossref]

53. Hayes SC, Strosahl K, Wilson KG (1999) Acceptance and commitment therapy: An experiential approach to behavior change. New York: Guilford Press.

Copyright: (C2020 Pruneti C. This is an open-access article distributed under the terms of the Creative Commons Attribution License, which permits unrestricted use, distribution, and reproduction in any medium, provided the original author and source are credited. 